\title{
Semiquantitative score of breast arterial calcifications on mammography (BAC-SS): intra- and inter-reader reproducibility
}

\author{
Rubina Manuela Trimboli ${ }^{1 *}$, Marina Codari $^{2 *} \wedge$, Andrea Cozzi ${ }^{1 \wedge}$, Caterina Beatrice Monti ${ }^{1 \wedge}$, \\ Davide Capra $^{1} \wedge$, Carolina Nenna ${ }^{3}$, Diana Spinelli ${ }^{4} \wedge$, Giovanni Di Leo ${ }^{5}$, Giuseppe Baselli ${ }^{2} \wedge$, \\ Francesco Sardanelli ${ }^{1,5} \wedge$
}

${ }^{1}$ Department of Biomedical Sciences for Health, Università degli Studi di Milano, Milan, Italy; ${ }^{2}$ Dipartimento di Elettronica, Informazione e Bioingegneria, Politecnico di Milano, Milan, Italy; ${ }^{3}$ Corso di Laurea in Medicina e Chirurgia, Università degli Studi di Milano, Milan, Italy; ${ }^{4}$ Postgraduation School in Radiodiagnostics, Università degli Studi di Milano, Milan, Italy; ${ }^{5}$ Unit of Radiology, IRCCS Policlinico San Donato, San Donato Milanese, Italy

Correspondence to: Davide Capra, MD. Department of Biomedical Sciences for Health, Università degli Studi di Milano, Via Mangiagalli 31 , 20133 Milan, Italy. Email: davide.capra@unimi.it.

\begin{abstract}
Background: Breast arterial calcifications (BAC), representing Mönckeberg's sclerosis of the tunica media of breast arteries, are an imaging biomarker for cardiovascular risk stratification in the female population. Our aim was to estimate the intra- and inter-reader reproducibility of a semiquantitative score for BAC assessment (BAC-SS).

Methods: Consecutive women who underwent screening mammography at our center from January $1^{\text {st }}$ to January $31^{\text {st }}, 2018$ were retrieved and included according to BAC presence. Two readers (R1 and R2) independently applied the BAC-SS to medio-lateral oblique views, obtaining a BAC score by summing: (I) number of calcified vessels (from 0 to $n$ ); (II) vessel opacification, i.e., the degree of artery coverage by calcium bright pixels (0 or 1); and (III) length class of calcified vessels (from 0 to 4). R1 repeated the assessment 2 weeks later. Scoring time was recorded. Cohen's $\kappa$ statistics and Bland-Altman analysis were used.

Results: Among 408 women, 57 (14\%) had BAC; 114 medio-lateral oblique views were assessed. Median BAC score was 4 [interquartile range (IQR): 3-6] for R1 and 4 (IQR: 2-6) for R2 (P=0.417) while median scoring time was $156 \mathrm{~s}$ (IQR: 99-314 s) for R1 and $191 \mathrm{~s}$ (IQR: 137-292 s) for R2 (P=0.743). Bland-Altman analysis showed a $77 \%$ intra-reader reproducibility [bias: 0.193 , coefficient of repeatability (CoR): 0.955] and a $64 \%$ inter-reader reproducibility (bias: 0.211, CoR: 1.516). Cohen's $\kappa$ for BAC presence was 0.968 for intra-reader agreement and 0.937 for inter-reader agreement.
\end{abstract}

Conclusions: Our BAC-SS has a good intra- and inter-reader reproducibility, within acceptable scoring times. A large-scale study is warranted to test its ability to stratify cardiovascular risk in women.

Keywords: Cardiovascular diseases; biomarkers; mammography; Mönckeberg medial calcific sclerosis; reproducibility of results

Submitted Apr 11, 2020. Accepted for publication Jan 05, 2021.

doi: $10.21037 /$ qims-20-560

View this article at: http://dx.doi.org/10.21037/qims-20-560

\footnotetext{
^ ORCID: Rubina Manuela Trimboli, 0000-0002-1502-0587; Marina Codari, 0000-0001-8475-2071; Andrea Cozzi, 0000-0003-4922-7065; Caterina Beatrice Monti, 0000-0002-9539-8642; Davide Capra, 0000-0001-7978-4730; Diana Spinelli, 0000-0002-3253-0108; Giovanni Di Leo, 0000-0003-0954-2634; Giuseppe Baselli, 0000-0003-2978-1704; Francesco Sardanelli, 0000-0001-6545-9427.

* Latest affiliation: Rubina Manuela Trimboli: Breast Imaging and Screening Unit, Department of Radiology, Humanitas Clinical and Research Center - IRCCS, via Manzoni 56, 20089 Rozzano, Italy; Marina Codari: Department of Radiology, Stanford University School of Medicine, 300 Pasteur Dr., Stanford, CA 94305, USA.
} 


\section{Introduction}

Recent data confirm that cardiovascular disease is the leading cause of death among women, accounting for about one-third of deaths (1). Multiple concerns have been raised over the lack of improvement in cardiovascular disease prevention in women $(2,3)$. Mortality rate for heart failure and stroke is higher in women than in men (4). In particular, in women aged 55 years or less, recent cardiovascular mortality has increased by $1 \%$ annually $(4,5)$. These trends reflect that traditional cardiovascular risk scores do not adequately perform in women, often underestimating cardiovascular risk (6). Hence, the prominence of unique non-traditional risk factors often translates in poorer outcomes $(3,7)$.

The development of innovative risk assessment strategies in women is crucial. In this light, breast arterial calcifications (BAC) have been identified as one of the most promising sex-specific imaging biomarkers for cardiovascular risk stratification in women (8). A recent meta-analysis from Hendriks et al. reported BAC to be associated with an increased cardiovascular risk (adjusted hazard ratios for coronary heart disease ranging from 1.32 to 1.44) (9). Moreover, a prospective study by Schnatz et al. (10) found that women with BAC were significantly more likely to develop heart disease or stroke than those without $\mathrm{BAC}(6.3 \%$ vs. $2.3 \%, \mathrm{P}=0.003 ; 58.3 \%$ vs. $13.3 \%$, $\mathrm{P}<0.001)$, respectively. Interestingly, Margolies et al. (11) firstly demonstrated a strong quantitative association of BAC with coronary artery calcium score on CT and its superiority to individual standard cardiovascular risk factors. This association reinforces the potential of BAC to ameliorate cardiovascular risk stratification in women erroneously classified at low-intermediate cardiovascular risk by traditional scores, without additional imaging, costs, or radiation exposure (12-17).

Currently, clinical application of BAC for cardiovascular risk stratification in women is limited (18). The greatest hindrance is the development of a reproducible, simple and quick method of BAC quantification that would allow the stratification in multiple classes of cardiovascular risk. A good reproducibility on a quantitative scale is the basic condition for deducing the diagnostic or prognostic power of a score, hence being the first step toward an objective BAC assessment and a subsequent risk stratification. In daily practice $\mathrm{BAC}$ are defined, when not ignored, as present or absent and this binary classification hinders the identification of women with intermediate risk, who likely might benefit from tailored preventive actions. Prospective studies with known and well defined cardiovascular outcomes will be thus necessary for identifying precise thresholds and, subsequently, populations subject to variable preventive interventions (19). Various strategies have been proposed to quantify BAC on a continuous or ordinal scale (20). Published studies range from manual estimation of BAC burden on both semiquantitative (11,21-23) and continuous scales $(24,25)$ to semiautomatic (26) and automatic segmentation algorithms $(27,28)$. However, only few of these solutions have had their reproducibility tested and largely vary in robustness $(21,22,25,26)$, thus reflecting the topological complexity of BAC as well as the absence of standardized criteria. Furthermore, no study assessed the application time of proposed scores, which instead represent a relevant issue in a daily clinical workflow.

Our aim was to evaluate intra-, inter-reader reproducibility and application time of a semiquantitative score for BAC assessment (BAC-SS) in a screening-like scenario, using routinely available standard software tools.

\section{Methods}

\section{Study population and image selection}

This retrospective, single center study focused on a subgroup of women included in a larger retrospective monocentric research project approved by the local Ethics Committee (Ethics Committee of IRCCS Ospedale San Raffaele; protocol code SenoRetro; approved on November $9^{\text {th }}, 2017$ and amended on July $\left.18^{\text {th }}, 2019\right)$. Informed consent was waived.

Mammograms of asymptomatic women who consecutively underwent breast cancer screening from January $1^{\text {st }}$ to January $31^{\text {st }}, 2018$ were retrieved. Mediolateral oblique views were evaluated for the presence of $\mathrm{BAC}$ and selected for analysis. Women's age was recorded.

\section{Image acquisition and assessment}

Mammograms were acquired using full-field digital systems (Giotto Tomo or Giotto Image 3D, IMS) and reviewed on standard 5-megapixel monitors with access to all standard software tools including magnification and gray-scale inversion.

The BAC-SS was defined as follows:

$$
\mathrm{BAC}-\mathrm{SS}=N_{v}+O_{v}+L
$$

where $N_{v}$ represents the number of calcified vessels; $O_{v}$ the vessel opacification and $L$ the length class of calcified 
Table 1 Variables and possible scores for assessing breast arterial calcifications using the BAC-SS system

\begin{tabular}{|c|c|}
\hline Variables & Definition \\
\hline Vessel opacification $\left(O_{v}\right)$ & $O_{v}=\left\{\begin{array}{l}0, \text { Visible arterial walls on MLO view } \\
1, \text { Opacified vessel with no visible arterial walls on MLO view }\end{array}\right.$ \\
\hline Length class of calcified segments $(L)$ & $L\left(l_{B A C}^{\dagger}\right)=\left\{\begin{array}{cc}0, & l_{B A C}=0 \mathrm{~mm} \\
1, & 0<l_{B A C} \leq Q_{1} \\
2, & Q_{1}<l_{B A C} \leq Q_{2} \\
3, & Q_{2}<l_{B A C} \leq Q_{3} \\
4, & l_{B A C}>Q_{3}\end{array}\right.$ \\
\hline BAC-SS & $\mathrm{BAC}-\mathrm{SS}=N_{v}+O_{v}+L$ \\
\hline
\end{tabular}

BAC segments. The vessel opacification $\left(O_{v}\right)$ was defined as "high" when the projection of calcium covered the arterial image from side to side with high-density pixels preventing the visualization of the non-calcified artery wall for at least $1 \mathrm{~mm}$ in length $\left(O_{v}=1\right)$, or "low" when no complete highdensity coverage from side to side was visible $\left(O_{v}=0\right)$.

To define $L$, the length of visible BAC $\left(l_{B A C}\right)$, obtained by summing the length of each calcified vessel segment ( $\mathrm{mm}$ ), was categorized into five classes. Patients without BAC were assigned to the 0 class, whereas the quartiles $\left(Q_{1}, Q_{2}\right.$ and $\left.Q_{3}\right)$ of $l_{B A C}$ distribution were set as threshold values, defining four classes for each corresponding quartile. Table 1 rigorously defines all variables that compose the BAC-SS, while Figure 1 represents an example of BAC-SS estimation from a single medio-lateral oblique view.

Medio-lateral oblique views were reviewed by a radiology resident with a 3 -year experience in reading mammography (R1) and by a medical student (R2) adequately trained for BAC identification by a radiologist with a 10 -year experience in breast imaging, in any case available for clarification. At first, both R1 and R2 performed a consensus review of a subgroup of 10 randomly selected exams, as training examples; subsequently, each reader independently evaluated all included mammograms. Application time was recorded for both readers on a subgroup of 10 subjects (20 medio-lateral oblique images), none of which had been included in the ten-subject subgroup used for initial training. Finally, to estimate intra-reader reproducibility, R1 reevaluated all selected mammograms in a separate session at a 2-week interval. Inter-reader reproducibility was evaluated between R1 first and R2 BAC-SS application.

\section{Statistical analysis}

The Shapiro-Wilk test was performed to ascertain data normality. If at least one distribution was non-normal, all data were treated with non-parametric statistics. Descriptive statistics of continuous variables were expressed as mean \pm standard deviation or median and interquartile range (IQR) according to data distribution. We used the $t$-test or the Mann-Whitney $U$ test to compare: age of women with BAC and age of women without BAC; median BAC-SS between the two readers; median BAC-SS in two age groups (50-69 years, $\geq 70$ years); median BAC-SS application time between the two readers.

To assess intra- and inter-reader reproducibility, Bland-Altman analysis was performed in case of discrete variables while Cohen's $\kappa$ statistics and raw concordance were used for categorical variables. Results of BlandAltman analysis were reported as bias, coefficient of repeatability (CoR), and reproducibility defined as the complement to one of the ratios between CoR and overall mean differences. Cohen's $\kappa$ with linear weighting for multiple categories was used with resulting values characterized according to the Landis and Koch scale (29): $<0$ no agreement; 0-0.20 slight agreement; 0.21-0.40 fair agreement; $0.41-0.60$ moderate agreement; $0.61-0.80$ substantial agreement; $0.81-1$ almost perfect agreement. The level of statistical significance was set at $\mathrm{P}<0.05$.

\section{Results}

A total of 408 asymptomatic women with a median age of 


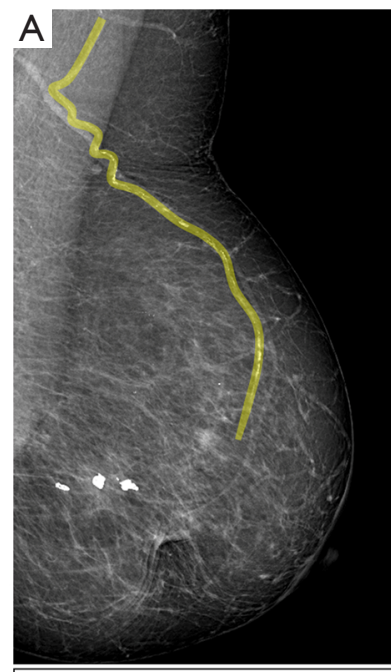

$N_{v}=1$

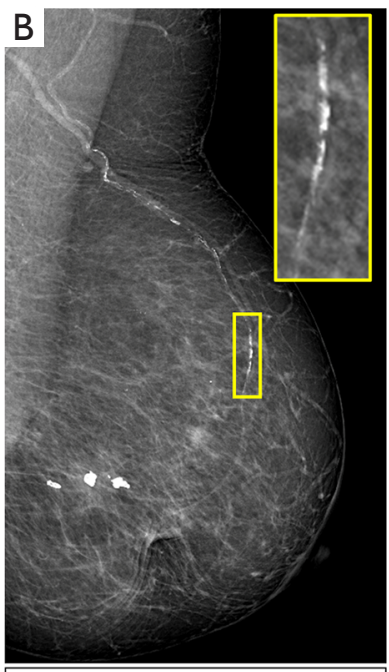

$O_{v}=1$

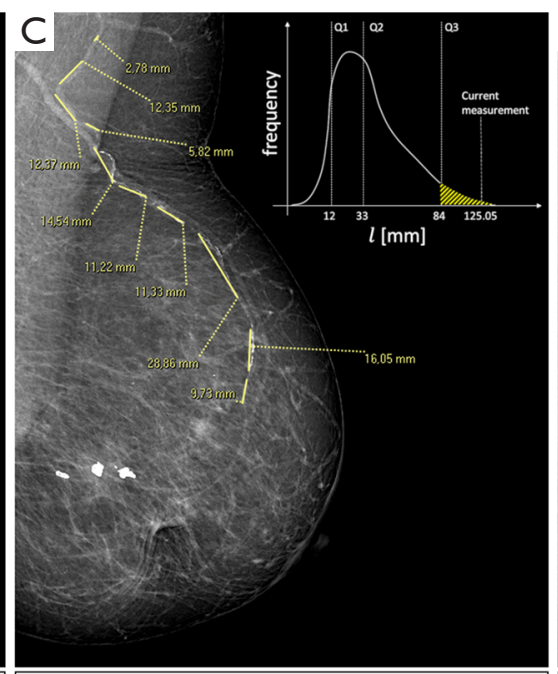

$I=125.05 \mathrm{~mm}$ $L_{v}=4$

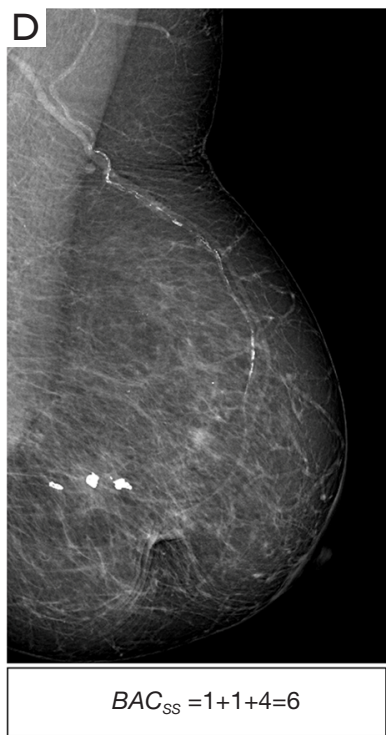

Figure 1 A medio-lateral oblique mammographic view with a BAC-SS of 6. In (A), a single involved vessel is visible, with a corresponding $N_{v}=1$. In (B), the vessel is opacified from side to side, with resulting $O_{v}$ of 1 . In $(\mathrm{C})$, the length of calcified segments $\left(l_{B A C}\right)$ resulted to be $125.05 \mathrm{~mm}$, belonging to the fourth quartile, with a corresponding L of 4. (D) The total BAC-SS was 6. BAC-SS, semiquantitative score for breast arterial calcifications assessment.

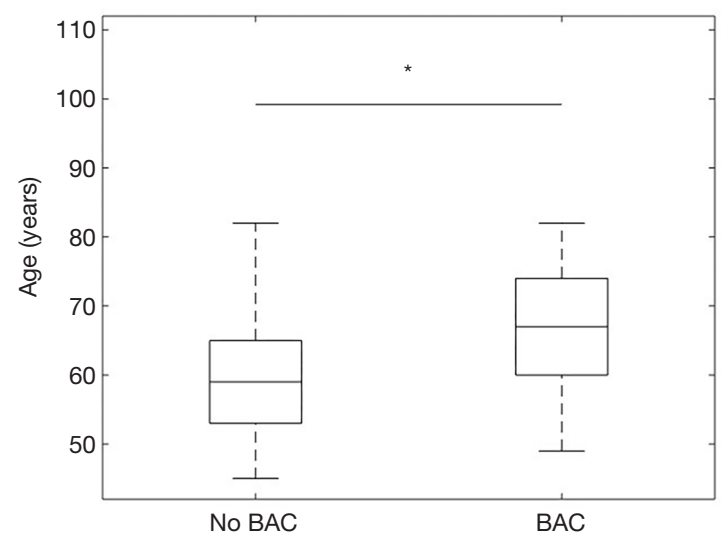

Figure 2 Boxplot of age distributions in women without and with BAC. * indicates that the comparison was statistically significant $(\mathrm{P}<0.001)$. BAC, breast arterial calcifications.

59 years (IQR: $53-67$ years, range: $45-82$ years) underwent mammography during the study period. Among these, 57 (14\%, 95\% confidence interval: $11-18 \%$ ) had BAC. As shown in Figure 2, women without BAC, with a median age of 59 years (IQR: $53-65$ years, range: $45-82$ years), were younger than women with BAC, who had a median age of
67 years (IQR: $60-74$ years, range: $49-82$ years $)(\mathrm{P}<0.001)$.

The BAC-SS was applicable in all 57 women; therefore 114 medio-lateral oblique views were evaluated. BAC presence was reported in $96 / 114$ and $95 / 114$ views in the first and second assessment by R1, respectively, with a raw concordance of $99 \%(\kappa=0.968, \mathrm{P}<0.001)$, and in $94 / 114$ views by R2. Comparing the first assessment by $\mathrm{R} 1$ and the assessment by R2, the raw concordance was $98 \%(\kappa=0.937$, $\mathrm{P}<0.001)$. According to R1, BAC were bilateral in $39 / 57$ and 38/57 women during the first and second assessment, respectively, with a raw concordance or $95 \%(\kappa=0.846$, $\mathrm{P}<0.001$ ), and in $37 / 57$ women by $\mathrm{R} 2$. Comparing the first assessment by R1 and the assessment by R2, the raw concordance was $96 \%(\kappa=0.921, \mathrm{P}<0.001)$. The median $l_{B A C}$ was $33 \mathrm{~mm}$ (IQR: $12-84 \mathrm{~mm}$ ). The median BAC-SS was 4 (IQR: 3-6) for the first assessment by R1, 4 (IQR: 3-5) for the second assessment by R1, and 4 (IQR: 2-6) for the assessment by $\mathrm{R} 2(\mathrm{P}=0.417)$. Bland-Altman plots of the intraand inter-reader reproducibility are shown in Figures 3,4.

In women aged 50-69 years, the median BAC-SS according to the first assessment by R1 was 4 (IQR: 3-5), while in women aged 70 or older it was significantly higher (5, IQR: 3-8, $\mathrm{P}=0.018$ ) as depicted in Figure 5.

Tables 2-5 detail the results of intra- and inter-reader agreement for dichotomic and categorical variables, and of 


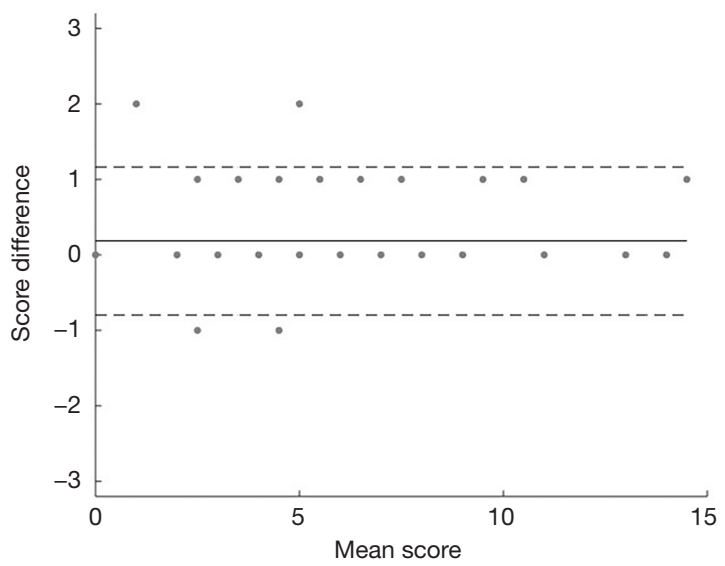

Figure 3 Bland-Altman plot for intra-reader reproducibility of the BAC-SS. BAC-SS, semiquantitative score for breast arterial calcifications assessment.

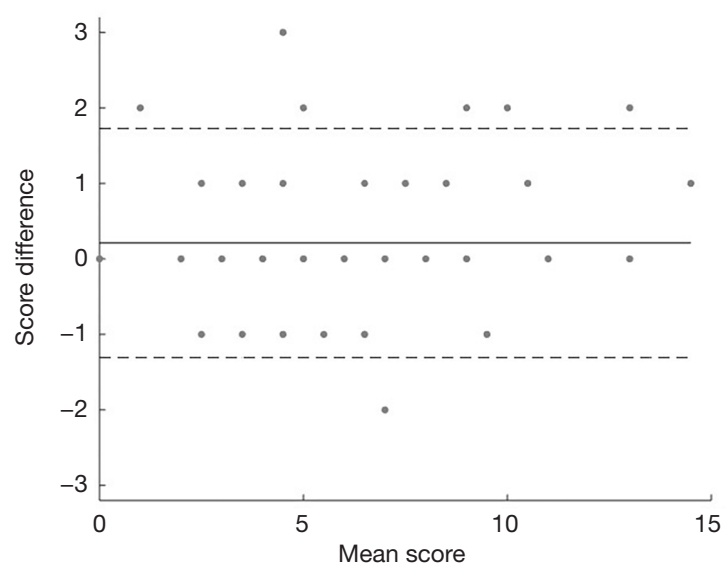

Figure 4 Bland-Altman plot for inter-reader reproducibility of the BAC-SS. BAC-SS, semiquantitative score for breast arterial calcifications assessment.

Table 2 Intra-reader agreement of dichotomic and categorical variables included in the semiquantitative score for assessing breast arterial calcifications (BAC-SS)

\begin{tabular}{lccc}
\hline $\begin{array}{l}\text { Dichotomic and } \\
\text { categorical variables }\end{array}$ & $\begin{array}{c}\text { Linear } \\
\text { weighted } \kappa\end{array}$ & P value & $\begin{array}{c}\text { Raw } \\
\text { concordance }\end{array}$ \\
\hline BAC presence/absence & 0.968 & $<0.001$ & $99 \%$ \\
BAC bilaterality & 0.846 & $<0.001$ & $95 \%$ \\
Vessel opacification $\left(O_{v}\right)$ & 0.961 & $<0.001$ & $99 \%$ \\
Length of calcified & 0.912 & $<0.001$ & $87 \%$ \\
vessels $(L)$ & & & \\
\hline
\end{tabular}

Dichotomic and categorical variables were analyzed with Cohen's $\kappa$ statistics. BAC, breast arterial calcifications.

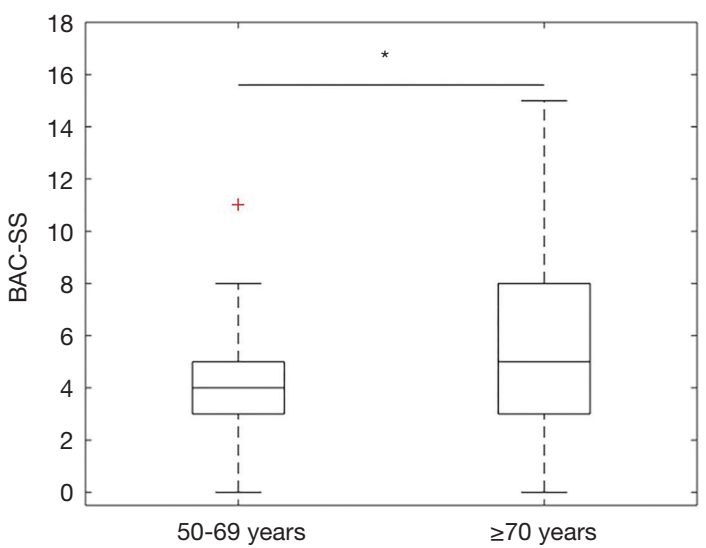

Figure 5 Boxplot of the BAC-SS obtained in patients aged 50-60 years or over 70 years. * indicates that the comparison was statistically significant $(\mathrm{P}=0.018)$. BAC-SS, semiquantitative score for breast arterial calcifications assessment.

Table 3 Intra-reader reproducibility of discrete variables and total semiquantitative score for assessing breast arterial calcifications (BAC-SS)

\begin{tabular}{lccc}
\hline Discrete variables & Bias & CoR & Reproducibility \\
\hline $\begin{array}{l}\text { Number of calcified } \\
\text { vessels }\left(N_{v}\right)\end{array}$ & 0.079 & 0.604 & $66 \%$ \\
BAC-SS & 0.193 & 0.955 & $77 \%$
\end{tabular}

Discrete variables were analyzed with Bland-Altman analysis. BAC, breast arterial calcifications; CoR, coefficient of repeatability.

Table 4 Inter-reader agreement of dichotomic and categorical variables included in the semiquantitative score for assessing breast arterial calcifications (BAC-SS)

\begin{tabular}{lccc}
\hline $\begin{array}{l}\text { Dichotomic and categorical } \\
\text { variables }\end{array}$ & $\begin{array}{c}\text { Linear } \\
\text { weighted } \kappa\end{array}$ & P value & $\begin{array}{c}\text { Raw } \\
\text { concordance }\end{array}$ \\
\hline BAC presence/absence & 0.937 & $<0.001$ & $98 \%$ \\
BAC bilaterality & 0.921 & $<0.001$ & $96 \%$ \\
Vessel opacification $\left(O_{v}\right)$ & 0.837 & $<0.001$ & $97 \%$ \\
Length of calcified vessels $(L)$ & 0.875 & $<0.001$ & $82 \%$ \\
\hline
\end{tabular}

Dichotomic and categorical variables were analyzed with Cohen's $\kappa$ statistics. BAC, breast arterial calcifications. 
Table 5 Inter-reader reproducibility of discrete variables and total semiquantitative score for assessing breast arterial calcifications (BAC-SS)

\begin{tabular}{lccc}
\hline Discrete variables & Bias & CoR & Reproducibility \\
\hline $\begin{array}{l}\text { Number of calcified } \\
\text { vessels }\left(N_{v}\right)\end{array}$ & 0.070 & 1.120 & $38 \%$ \\
BAC-SS & 0.211 & 1.516 & $64 \%$ \\
\hline
\end{tabular}

Discrete variables were analyzed with Bland-Altman analysis. BAC, breast arterial calcifications; CoR, coefficient of repeatability.

intra- and inter-reader reproducibility for discrete variables.

The median application time was $156 \mathrm{~s}$ (IQR: 99-314 s) for the first assessment by R1 and $191 \mathrm{~s}$ (IQR: 137-292 s) for R2 $(\mathrm{P}=0.743)$.

\section{Discussion}

The main aim of our study was to propose a simple method for quantifying BAC on mammograms. By combining the number of calcified vessels, vessel opacification, and length of calcified vessels we obtained a semiquantitative score, the BAC-SS, that showed a $77 \%$ intra-reader reproducibility and a $64 \%$ inter-reader reproducibility and could be applied in clinical practice in about 2-3 min by breast radiologists. This result has to be placed into the context of the current status of the emergent need to improve cardiovascular disease prevention in women.

In fact, non-traditional risk factors unique or predominant to women have to be advocated for a sexspecific risk assessment, crucial for a better outcome. Efforts have been undertaken to improve the performance of traditional cardiovascular risk scores with the help of algorithms and imaging biomarkers (26).

BAC have been recently described among "the top five women's health issues in preventive cardiology, at the forefront of recent and ongoing research", together with coronary microvascular dysfunction, hormone replacement therapy, calcium and vitamin D supplementation, and metabolic adaptations during pregnancy (30). Indeed, breast cancer is also a well-known health problem, thus women entering mammographic screening would benefit from both breast cancer and cardiovascular prevention. BAC are commonly seen on mammograms as linear, parallel opacities, typically with a "tram-track" appearance $(9,17,20,31)$. They are the expression of Mönckeberg's sclerosis, a non-atheromatous vascular lesion developing in the internal elastic lamina or in the tunica media of muscular arteries and containing hydroxyapatite crystal deposition in the plaques (32), to be distinguished from intima atherosclerotic calcifications including calcium phosphate salts in the vascular tissue. The reported association between BAC and cardiovascular risk factors was displayed by a meta-analysis $(9,33)$ that found high pooled BAC prevalence correlated with increasing age, diabetes, hypertension, and parity as opposed to nulliparity, while smoking was linked with lower BAC prevalence.

We found a BAC prevalence of $57 / 408$ (14\%), in line with data from the literature showing a prevalence around $12.7 \%$ among women in breast cancer screening programs (9). We also found a significant difference $(\mathrm{P}<0.001)$ for age between 57 women with BAC (aged $67 \pm 9$ years) and 351 women without BAC (aged $59 \pm 8$ years), confirming that BAC prevalence increases with age, like cardiovascular risk, considering the loss of protective role of estrogenic hormones after menopause. This evidence advocates for the use of mammography as a preventive test beyond breast cancer screening, spotlighting both the heart and cardiovascular risk (20).

Attempts have been made to improve BAC estimation using fully automated methods or qualitative and quantitative approaches $(11,21,34,35)$ but reproducibility of semiquantitative BAC grading scales has been scarcely explored. A previous experience (26) using a semiautomatic continuous scale showed a huge operator dependence, prompting the development of new tools. Conversely, our BAC-SS system showed a $77 \%$ intra-reader and a $64 \%$ inter-reader reproducibility, opening a perspective for large studies exploring its ability to stratify cardiovascular risk in women.

Among the parameters considered to obtain the BACSS, the number of calcified vessels was the most difficult to be assessed, showing the lowest reproducibility compared to vessel opacification and the length of calcified vessels. Defining when a major vessel stops giving rise to separate branches and how many branches have to be considered turned out not to be an easy task. Conversely, the vessel opacification and the length of calcified segments showed a high intra- and inter-reader agreement. In fact, raw concordance values confirm the high level of agreement of those categorical variables. Our aim was to propose and test a robust and reproducible method that could provide an effective indirect marker rather than a physical estimation of the calcium within the walls of the breast vessels. We are aware about the partial redundancy in information content of $N_{v}$ (number of involved vessels) 
and $L$ (length of BAC segments) variables. Nevertheless, we initially decided to keep those variables as separate to depict two different scenarios: a woman with a single vessel extensively involved by BAC $\left(N_{v}=1, L>3\right)$ and a woman with several small calcifications in different vessels $\left(N_{v}>1, L>3\right)$, which are undistinguishable when considering only the $\mathrm{L}$ variable. This will allow us to evaluate in future investigations the possible effect of those different conditions on cardiovascular risk stratification.

Moreover, to take into account the high variability of length measurement over a continuous scale $(\mathrm{mm})$ we categorized the continuous measurements into four classes according to the quartiles of distribution of BAC length. This allowed us to improve measurement reproducibility without explicitly define a priori length thresholds, which are derived from BAC length distribution nonparametric statistics of the analyzed sample. The high inter-reader agreement of the length class feature $(\kappa=0.875, \mathrm{P}<0.001)$ seems to confirm our assumption.

We also observed that BAC-SS application time for both readers was about 2-3 minutes, suitable for integration in clinical practice. Of note, the automatization of a timeconsuming task as the calculation of BAC lengths, which took an average 1 minute for both readers, could allow for even smoother inclusion.

The potential of artificial intelligence for BAC detection and quantification has been investigated: a deep convolutional neural network was used to discriminate BAC from non-BAC pixels (28), reaching a detection ability similar to that of human experts, with good performance also in calcium mass quantification. Further studies are needed to validate these algorithms.

Our study has limitations. First, it is a retrospective single-center study on a relatively small number of subjects. Second, the two human readers were a resident and a medical student who-although adequately trainedstill had limited general experience in medical imaging. Nevertheless, agreement rates fell into the highest category according to the Landis and Koch classification (29) and this is reassuring. Experienced readers may possibly have a higher reproducibility, even if, differently from parenchymal calcifications deemed to be malignant, in this context, the human identification of BAC represents the main source of variability (26). Third, a "ground truth" for BAC was not applied. It is unlikely that we will ever have prospective studies ascertaining arterial calcium burden from surgical specimens.

In conclusion, the proposed BAC-SS allowed to quantify
BAC on mammography with good reproducibility and within an acceptable time, allowing for a potential clinical translation at a very low cost on a large scale. Prospective trials on large population with and without known cardiovascular risk and events are needed to prove the ability of this score to stratify cardiovascular risk improving cardiovascular health in women.

\section{Acknowledgments}

We thank all the personnel of IRCCS Policlinico San Donato for their support. Preliminary results of this paper were accepted at the European Congress of Radiology 2020.

Funding: This study was partially supported by Ricerca Corrente funding from Italian Ministry of Health to IRCCS Policlinico San Donato.

\section{Footnote}

Conflicts of Interest: All authors have completed the ICMJE uniform disclosure form (available at http://dx.doi. org/10.21037/qims-20-560). FS has received research grants from and is member of speakers' bureau and of advisory group for General Electric, Bayer, and Bracco. The other authors have no conflicts of interest to declare.

Ethical Statement: This retrospective, single center study focused on a subgroup of women included in a larger retrospective monocentric research project approved by the local Ethics Committee (Ethics Committee of IRCCS Ospedale San Raffaele; protocol code SenoRetro; approved on November $9^{\text {th }}, 2017$ and amended on July $\left.18^{\text {th }}, 2019\right)$. Informed consent was waived.

Open Access Statement: This is an Open Access article distributed in accordance with the Creative Commons Attribution-NonCommercial-NoDerivs 4.0 International License (CC BY-NC-ND 4.0), which permits the noncommercial replication and distribution of the article with the strict proviso that no changes or edits are made and the original work is properly cited (including links to both the formal publication through the relevant DOI and the license). See: https://creativecommons.org/licenses/by-nc-nd/4.0/.

\section{References}

1. GBD 2017 Causes of Death Collaborators. Global, regional, and national age-sex-specific mortality for 282 
causes of death in 195 countries and territories, 1980-2017: a systematic analysis for the Global Burden of Disease Study 2017. Lancet 2018;392:1736-88.

2. Garcia M, Mulvagh SL, Bairey Merz CN, Buring JE, Manson JE. Cardiovascular disease in women. Circ Res 2016;118:1273-93.

3. Hyun KK, Redfern J, Patel A, Peiris D, Brieger D, Sullivan D, Harris M, Usherwood T, MacMahon S, Lyford M, Woodward M. Gender inequalities in cardiovascular risk factor assessment and management in primary healthcare. Heart 2017;103:492-8.

4. Benjamin EJ, Muntner P, Alonso A, Bittencourt MS, Callaway CW, Carson AP, Chamberlain AM, Chang AR, Cheng S, Das SR, Delling FN, Djousse L, Elkind MSV, Ferguson JF, Fornage M, Jordan LC, Khan SS, Kissela BM, Knutson KL, Kwan TW, Lackland DT, Lewis TT, Lichtman JH, Longenecker CT, Loop MS, Lutsey PL, Martin SS, Matsushita K, Moran AE, Mussolino ME, O'Flaherty M, Pandey A, Perak AM, Rosamond WD, Roth GA, Sampson UKA, Satou GM, Schroeder EB, Shah SH, Spartano NL, Stokes A, Tirschwell DL, Tsao CW, Turakhia MP, VanWagner LB, Wilkins JT, Wong SS, Virani SS. Heart disease and stroke statistics—2019 update: a report from the American Heart Association. Circulation 2019;139:e56-528.

5. Piepoli MF, Hoes AW, Agewall S, Albus C, Brotons C, Catapano AL, Cooney M-T, Corrà U, Cosyns B, Deaton C, Graham I, Hall MS, Hobbs FDR, Løchen M-L, Löllgen H, Marques-Vidal P, Perk J, Prescott E, Redon J, Richter DJ, Sattar N, Smulders Y, Tiberi M, van der Worp HB, van Dis I, Verschuren WMM. 2016 European Guidelines on cardiovascular disease prevention in clinical practice. Eur Heart J 2016;37:2315-81.

6. Kelkar AA, Schultz WM, Khosa F, Schulman-Marcus J, O'Hartaigh BWJ, Gransar H, Blaha MJ, Knapper JT, Berman DS, Quyyumi A, Budoff MJ, Callister TQ, Min JK, Shaw LJ. Long-term prognosis after coronary artery calcium scoring among low-intermediate risk women and men. Circ Cardiovasc Imaging 2016;9:e003742.

7. Wenger NK. Transforming cardiovascular disease prevention in women: time for the pygmalion construct to end. Cardiology 2015;130:62-8.

8. Suh JW, Yun B. Breast arterial calcification: a potential surrogate marker for cardiovascular disease. J Cardiovasc Imaging 2018;26:125-34.

9. Hendriks EJEE, De Jong PA, van der Graaf Y, Mali WPTTM, van der Schouw YT, Beulens JWJJ. Breast arterial calcifications: a systematic review and meta- analysis of their determinants and their association with cardiovascular events. Atherosclerosis 2015;239:11-20.

10. Schnatz PF, Marakovits KA, O'Sullivan DM. The association of breast arterial calcification and coronary heart disease. Obstet Gynecol 2011;117:233-41.

11. Margolies L, Salvatore M, Hecht HS, Kotkin S, Yip R, Baber U, Bishay V, Narula J, Yankelevitz D, Henschke C. Digital mammography and screening for coronary artery disease. JACC Cardiovasc Imaging 2016;9:350-60.

12. Mendonça RM, Araruna AL, Alves FV, Souza TR, Egito EST, Gonçalves AK. Role of breast vascular calcification in predicting cardiovascular risk. Int J Gynaecol Obstet 2019;144:232-3.

13. Lin X, Yuan LQ, Liu YS. Could breast arterial calcification predict the risk of coronary artery disease? JACC Cardiovasc Imaging 2018;11:1932.

14. Mantas D, Markopoulos C. Screening mammography: usefulness beyond early detection of breast cancer. Atherosclerosis 2016;248:1.

15. Zuin M, Rigatelli G, Scaranello F, Ribecco SG, Picariello C, Zuliani G, Faggian G, Zonzin P, Roncon L. Breast arterial calcifications on mammography and coronary artery disease: a new screening tool for cardiovascular disease? Int J Cardiol 2016;220:310-1.

16. Cainzos-Achirica M, Tota-Maharaj R. Breast arterial calcification for personalized cardiovascular risk assessment: where do we stand? Atherosclerosis 2017;259:101-3.

17. Bui QM, Daniels LB. A review of the role of breast arterial calcification for cardiovascular risk stratification in women. Circulation 2019;139:1094-101.

18. Trimboli RM, Capra D, Codari M, Cozzi A, Di Leo G, Sardanelli F. Breast arterial calcifications as a biomarker of cardiovascular risk: radiologists' awareness, reporting, and action. A survey among the EUSOBI members. Eur Radiol 2021;31:958-66.

19. Degrell P, Sorbets E, Feldman LJ, Steg PG, Ducrocq G. Screening for coronary artery disease in asymptomatic individuals: why and how? Arch Cardiovasc Dis 2015;108:675-82.

20. Trimboli RM, Codari M, Guazzi M, Sardanelli F. Screening mammography beyond breast cancer: breast arterial calcifications as a sex-specific biomarker of cardiovascular risk. Eur J Radiol 2019;119:108636.

21. Mostafavi L, Marfori W, Arellano C, Tognolini A, Speier W, Adibi A, Ruehm SG. Prevalence of coronary artery disease evaluated by coronary CT angiography in women with mammographically detected breast arterial 
calcifications. PLoS One 2015;10:e0122289.

22. Ružičić D, Dobrić M, Vuković M, Hrnčić D, Đorđević S, Ružičić M, Aleksandrić S, Đorđević-Dikić A, Beleslin B. The correlation of SYNTAX score by coronary angiography with breast arterial calcification by digital mammography. Clin Radiol 2018;73:454-9.

23. Kelly BS, ScanlON E, Heneghan H, Redmond CE, Healy GM, Mc Dermott E, Heffernan EJ, Prichard R, Mc Nally S. Breast arterial calcification on screening mammography can predict significant coronary artery disease in women. Clin Imaging 2018;49:48-53.

24. Molloi S, Xu T, Ducote J, Iribarren C. Quantification of breast arterial calcification using full field digital mammography. Med Phys 2008;35:1428-39.

25. Molloi S, Mehraien T, Iribarren C, Smith C, Ducote JL, Feig SA. Reproducibility of breast arterial calcium mass quantification using digital mammography. Acad Radiol 2009; 16:275-82.

26. Trimboli RM, Codari M, Bert A, Carbonaro LA, Maccagnoni S, Raciti D, Bernardi D, Clauser P, Losio C, Tagliafico A, Sardanelli F. Breast arterial calcifications on mammography: intra- and inter-observer reproducibility of a semi-automatic quantification tool. Radiol Med 2018;123:168-73.

27. Cheng JZ, Chen CM, Cole EB, Pisano ED, Shen D. Automated delineation of calcified vessels in mammography by tracking with uncertainty and graphical linking techniques. IEEE Trans Med Imaging 2012;31:2143-55.

28. Wang J, Ding H, Bidgoli FA, Zhou B, Iribarren C,

Cite this article as: Trimboli RM, Codari M, Cozzi A, Monti CB, Capra D, Nenna C, Spinelli D, Di Leo G, Baselli G, Sardanelli F. Semiquantitative score of breast arterial calcifications on mammography (BAC-SS): intraand inter-reader reproducibility. Quant Imaging Med Surg 2021;11(5):2019-2027. doi: 10.21037/qims-20-560
Molloi S, Baldi P. Detecting cardiovascular disease from mammograms with deep learning. IEEE Trans Med Imaging 2017;36:1172-81.

29. Landis JR, Koch GG. The measurement of observer agreement for categorical data. Biometrics 1977;33:159-74.

30. Abouzeid C, Bhatt D, Amin N. The top five women's health issues in preventive cardiology. Curr Cardiovasc Risk Rep 2018;12:6.

31. Polonsky TS, Greenland P. Breast Arterial Calcification. Circulation 2017;135:499-501.

32. Micheletti RG, Fishbein GA, Currier JS, Fishbein MC. Mönckeberg sclerosis revisited: a clarification of the histologic definition of Mönckeberg sclerosis. Arch Pathol Lab Med 2008;132:43-7.

33. Lee SC, Phillips M, Bellinge J, Stone J, Wylie E, Schultz C. Is breast arterial calcification associated with coronary artery disease?-A systematic review and meta-analysis. PLoS One 2020;15:e0236598.

34. Newallo D, Meinel FG, Schoepf UJ, Baumann S, De Cecco CN, Leddy RJ, Vliegenthart R, Möllmann H, Hamm CW, Morris PB, Renker M. Mammographic detection of breast arterial calcification as an independent predictor of coronary atherosclerotic disease in a single ethnic cohort of African American women. Atherosclerosis 2015;242:218-21.

35. Chadashvili T, Litmanovich D, Hall F, Slanetz PJ. Do breast arterial calcifications on mammography predict elevated risk of coronary artery disease? Eur J Radiol 2016;85:1121-4. 